\title{
Rockburst Monitoring in Deep Coalmines with Protective Coal Panels Using Integrated Microseismic and Computed Tomography Methods
}

\author{
Dong $\mathrm{Li}^{1}$ and Junfei Zhang $\mathrm{DD}^{2}$ \\ ${ }^{1}$ School of Safety Engineering, North China Institute of Science and Technology, Beijing 101601, China \\ ${ }^{2}$ School of Civil, Environmental and Mining Engineering, The University of Western Australia, Perth 6009, Australia \\ Correspondence should be addressed to Junfei Zhang; junfeizhang2010@gmail.com
}

Received 31 May 2020; Revised 9 August 2020; Accepted 16 August 2020; Published 26 August 2020

Academic Editor: Bangyou Jiang

Copyright (C) 2020 Dong Li and Junfei Zhang. This is an open access article distributed under the Creative Commons Attribution License, which permits unrestricted use, distribution, and reproduction in any medium, provided the original work is properly cited.

In deep coalmines, longwall panels are subject to high static initial geostress andhigh dynamic stress caused by mining and tunnelling activities. Under the action of high static and dynamic stress, rockburst hazards are very likely to occur. To reduce rockburst risks, protective panels are commonly applied in deep coalmines. However, stress concentration in the protective coal panel often causes rockburst hazards in the gateway of the next longwall panel pending mining. To reduce such type of rockburst, this study firstly proposes a mathematic model to analyse the overall static stress distribution in the protective panel based on the mining practice in Longyun coalmine, Shandong Province, China. To evaluate the stress concentration caused by geological defects in the protective panel, a new rockburst evaluation index is proposed based on the computed tomography (CT) method. Finally, the extent of dynamic stress evolution caused by different working face advancing velocities is determined by microseismic monitoring. Results show that the areas with higher rockburst evaluation indexes are highly associated with the areas with large-energy microseismic events, indicating that the static stress concentration can be accurately identified by the CT method. A medium advancing velocity $(4.0 \mathrm{~m} / \mathrm{s})$ is recommend during mining the longwall panel, which can ensure mining safety and improve mining productivity simultaneously. The integrated microseismic and CT monitoring methods can be used in other underground projects to guarantee construction safety and productivity.

\section{Introduction}

With the increase in operating depth of coalmines, the longwall panels are subject to higher initial geostress. As a result, dynamic disasters such as rockbursts occur more and more frequently [1]. Rockburst is induced by the sudden release of elastic strain energy when the mechanical state of the surrounding rock or coal is unstable. This kind of energy release is usually violent, sharp, and associated with dynamic phenomena such as rock ejection, spalling, and slabbing [2-4]. This catastrophic disaster has caused a large number of casualties and property losses in underground mines $[5,6]$. The accurate evaluation of rockburst risks is the main bottleneck for mining in deep coalmines [7].
To reduce rockburst risks, protective panels are commonly applied in deep coalmines [8]. The protective panel is actually a special type of coal pillar with large width. After the longwall panels on both sides of the protective panels are mined, the protective panel will become an island coal panel. This panel is subject to high abutment stress of the previous mined panel, and therefore, the gateway of the next longwall panel adjacent to the protective panel is at high rockburst risk. The distribution of abutment stress in the island panel has been extensively studied by empirical mathematical equations and numerical simulation. Huang et al. applied FLAC 3D to study the magnitude and position of abutment stress in the island panel [9]. Zhu et al. established a mathematical equation of abutment stress distribution on an island panel based on subsidence theory and proposed the 
rockburst index for evaluating the overall instability of an island longwall panel [10]. However, most of the research studies focus on the stress distribution in island coal panels. Few studies have been carried out to analyse rockburst that occurred in the gateway between the protective panel and the longwall panel pending mining. Therefore, this study proposes a mathematical model to evaluate the distribution of abutment stress in the protective panel.

The theoretical models are generally used to evaluate the overall rockburst risk. As a variety of geological defects cannot be taken into account [11-15], field monitoring is usually used to calibrate these models, that is, to figure out the stress concentration caused by some unknown or unconsidered geological defects. Recently, the seismic computed tomography (CT) technique has been introduced to assess the distribution of abutment stress in underground coalmines [16-18]. According to the types of wave sources, seismic CT can be divided into "active" and "passive" [19]. The sources of active CT are generated by cutting equipment, hammer strikes, or controlled explosives at a known position, while the sources of passive CT are seismic events due to fracture of rock mass. Therefore, passive CT can be used to continuously detect stress distribution in underground mines. The CT technique was traditionally adopted to analyse the relationship between the stress and the ultrasonic wave velocity for the rock samples under loads [20]. Dou et al. investigated the relationship between the abutment stress and the wave velocity of seismic CT and found that the stress changes are reflected by the anomaly of elastic wave velocity [16]. Cai et al. compared the difference between active and passive tomography in monitoring abutment stress distribution [17]. The relationship between passive tomographic velocity and seismic intensity around an island longwall panel was studied by Cao et al. [18]. The abovementioned studies infer the stress field of the rock mass using P-wave velocity to indirectly detect the areas with rockburst potential. However, quantitative analysis of tomography velocity based on velocity anomaly and velocity gradient for direct evaluation of rockburst hazards has not yet been proposed. Therefore, this study proposes a rockburst risk evaluation index by integrating velocity anomaly and velocity gradient to evaluate rockburst hazards in protective panels and gateways.

It is known that high static stress (abutment stress) is the necessary but not sufficient condition for rockburst occurrence, and dynamic stress (seismic wave) due to mining or tunnelling activities is the main inducing factor for rockburst hazards [21]. The cracks caused by the dynamic stress within the rock mass can be detected by the real-time microseismic monitoring technique that can capture the occurrence time, location, and intensity of cracks [22-24]. Furthermore, the initiation, propagation, and nucleation of the microcracks to large-scale fractures can be assessed by studying the evolution of the recorded microseismic monitoring data. The microseismic monitoring technique has been employed to study rockbursts in underground mines for many decades. Cook et al. firstly gained a significant insight into the fundamental nature of the rockburst problem by using the seismic data of the East Rand
Proprietary Mines [25]. Srinivasan et al. assessed rockburst hazards at the Kolar gold mines using the rate of change of the microseismic event count, strain energy release, and predominant signal frequency as the reliable short-term precursors [26]. Leśniak and Isakow assessed rockburst hazards by space-time clustering of seismic events [27]. Lu et al. predicted rockburst hazards based on the microseismic indexes: corresponding energy ratio, dominant frequency, $z$ value, $b$ value, and energy and event count [28]. Microseismic signal processing methods such as signal filtering, source location, and first-arrival picking in a field hydraulic fracturing test in a coalmine were discussed by Zhu et al. [29]. This previous literature provides sufficient theoretical foundation for evaluating rockburst hazards in deep coalmines. However, the evolution of dynamic stress is highly dependent on the working face advancing velocity. A higher velocity will cause faster evolution of dynamic stress in the overlying strata, resulting in more fractures in the rock mass during mining, while a lower advancing velocity may reduce the productivity. Therefore, it is necessary to provide an appropriate advancing velocity to ensure both mining safety and productivity using microseismic monitoring.

To address these abovementioned problems, this study will

(1) propose a mathematical model to evaluate the overall distribution of abutment stress in the protective panel and the gateway of the next panel pending mining,

(2) analyse the static stress concentration caused by geological defects that are not considered in the previous mathematical model using the seismic CT method. In this method, a rockburst risk evaluation index will be proposed combining velocity anomaly and velocity gradient, and

(3) determine an appropriate working face advancing velocity to reach a compromise between mining safety and productivity using microseismic monitoring.

\section{Geological Setting and Rockburst Hazards in Longyun Coalmine}

Longyun coalmine is owned by Longyun Coal Mining Co. Ltd. in Yuncheng County, Shandong Province, China, as shown in Figure 1. This coalmine obtained the first mining license in April 2007. Its mining depth ranges from $450 \mathrm{~m}$ to $1750 \mathrm{~m}$ with an approved production capacity of 2.4 million t/a. Currently, coal seam 3 with an average thickness of $6.71 \mathrm{~m}$ and an average operation depth of $1000 \mathrm{~m}$ is being mined. The longwall panels arranged in coal seam 3 are shown in Figure 2. The fully mechanized top-coal caving mining method is used in this mine. There exists a large protective coal panel of $80 \mathrm{~m}$ between LW 1301 and LW 1300 to ensure mining safety when mining LW 1301. The formation of main roof is complex and mainly composed of sandstone, mudstone, and top soil, as shown in Figure 3.

Three rockburst accidents occurred in the headgate of LW 1301 when mining LW 1300 on 5th September 2014, 5th 


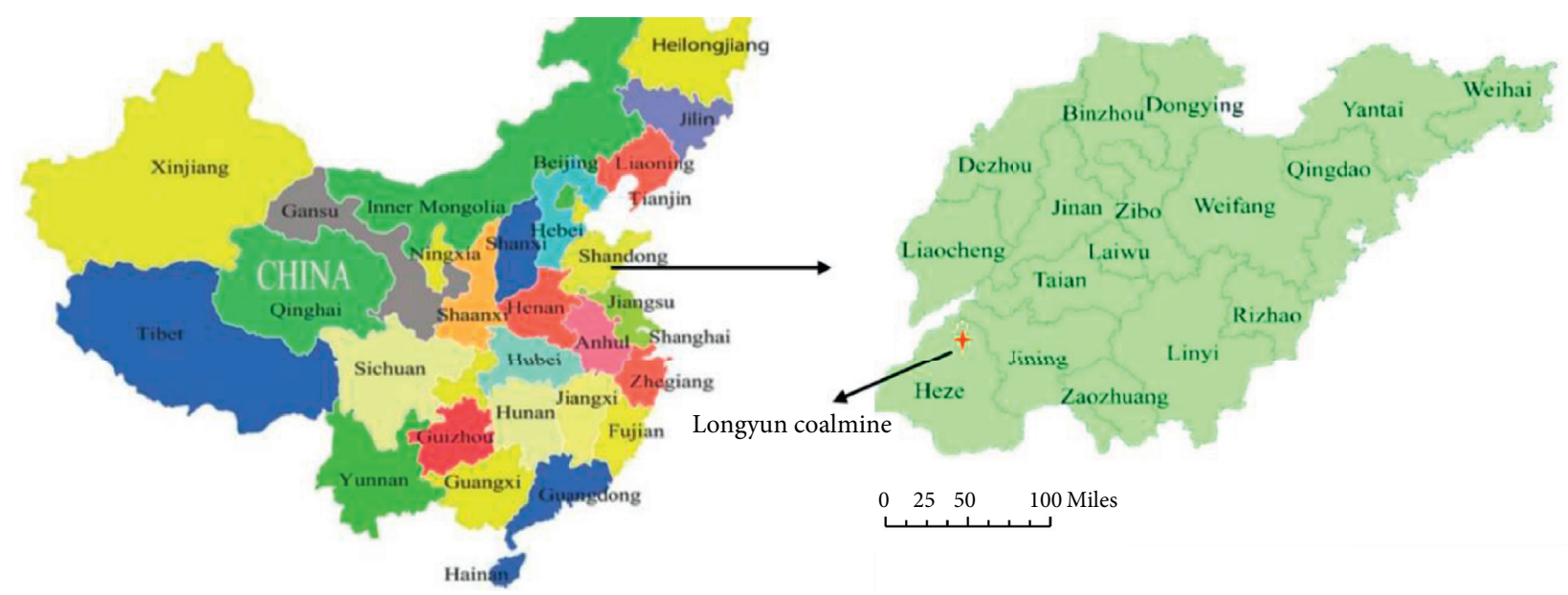

FIgURE 1: Location of Longyun coalmine in Shandong Province, China.

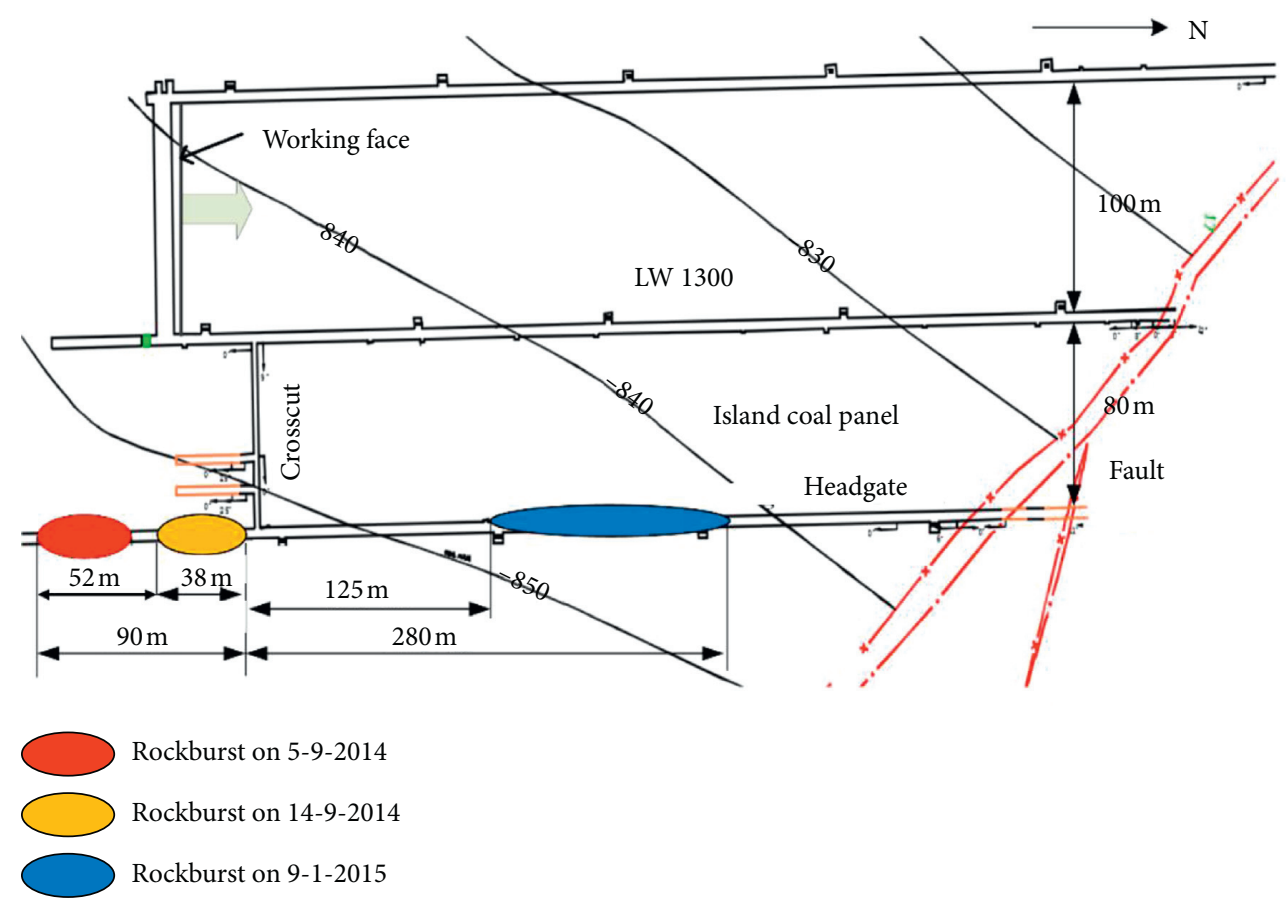

FIGURE 2: Layout of the stope in Longyun coalmine and rockburst areas on 5th September 2014 (a), 14 th September 2014 (b), and 1st September 2015 (c).

September 2014, and 1st September 2015 (Figure 2), respectively. Roof caving and tunnel squeezing as well as different kinds of damages of steel belt were observed in the three rockburst accidents (Figure 2). It can be seen that the influencing area of the rockburst occurring on 1st September 2015 is the largest. In this accident, about $45 \mathrm{~m}$ long roadway was severely squeezed: the diameter of the roadway is reduced by over $1 \mathrm{~m}$.

\section{Computed Topography}

3.1. Theoretical Foundation of Computed Topography. Generally, the blasting sources are deployed in the headgate of the longwall panel, and the receivers (usually geophones) are deployed in the tailgate. Assume that seismic waves propagate in the form of rays in the internal medium of the detection zone. The travel time of a seismic wave can be formulated as follows:

$$
t_{i}=\frac{d s_{i}}{v_{i}}=s_{i} d s_{i},
$$

where $t_{i}$ denotes the travel time of the $i$ th seismic wave; $d s_{i}$ is the infinitesimal arc of the $i$ th seismic wave; $v_{i}$ is the velocity of the $i$ th seismic wave; and $s_{i}=1 / v_{i}$ is the slowness of the $i$ th seismic wave. As the rock mass is heterogeneous, the propagation path of a seismic wave is not a straight line. Therefore, the inversion area must be discretised into $M$ grids and the travel time of the $i$ th seismic wave in the $j$ th grid can be formulated as 

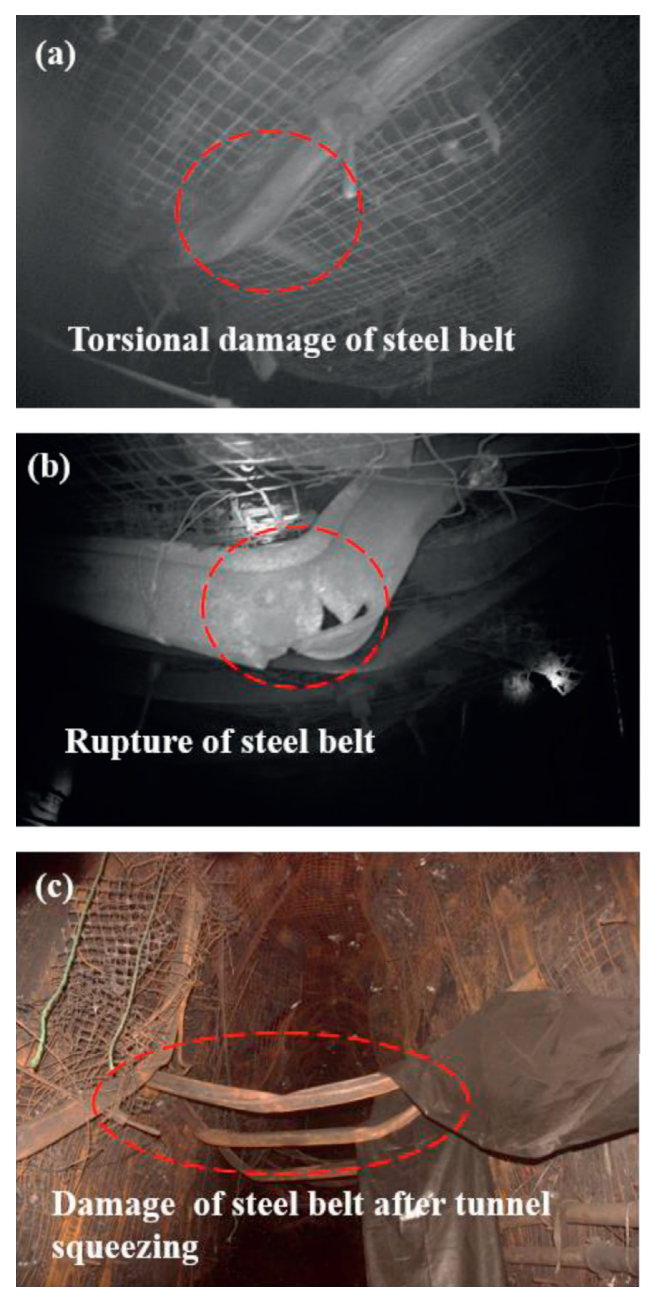

Figure 3: Photos of rockburst that occurred on 5th September 2014 (a), 5th September 2014 (b), and 1st September 2015 (c) and lithologic distribution in the main roof.

$$
t_{i}=\sum_{j=1}^{M} d_{i j} s_{j},
$$

where $d_{i j}$ is the propagation length of the $i$ th seismic wave in the $j$ th grid. The above equation can be organized as the following matrix:

$$
T=D S \longrightarrow S=D^{-1} T,
$$

where $T$ is the column vector of travel times; $D$ denotes the matrix of propagation distance; and $S$ represents the column vector of slowness values. To solve the above inverse problem, the simultaneous iterative reconstruction technique (SIRT) is commonly applied as it is reliable and stable with fast converging speed and low sensitivity to projection data errors [30-32].

3.2. Rockburst Risk Evaluation Based on Seismic Velocity Structure. In stress concentration areas, velocity anomaly of the seismic wave will appear, which can be defined as follows [33]:

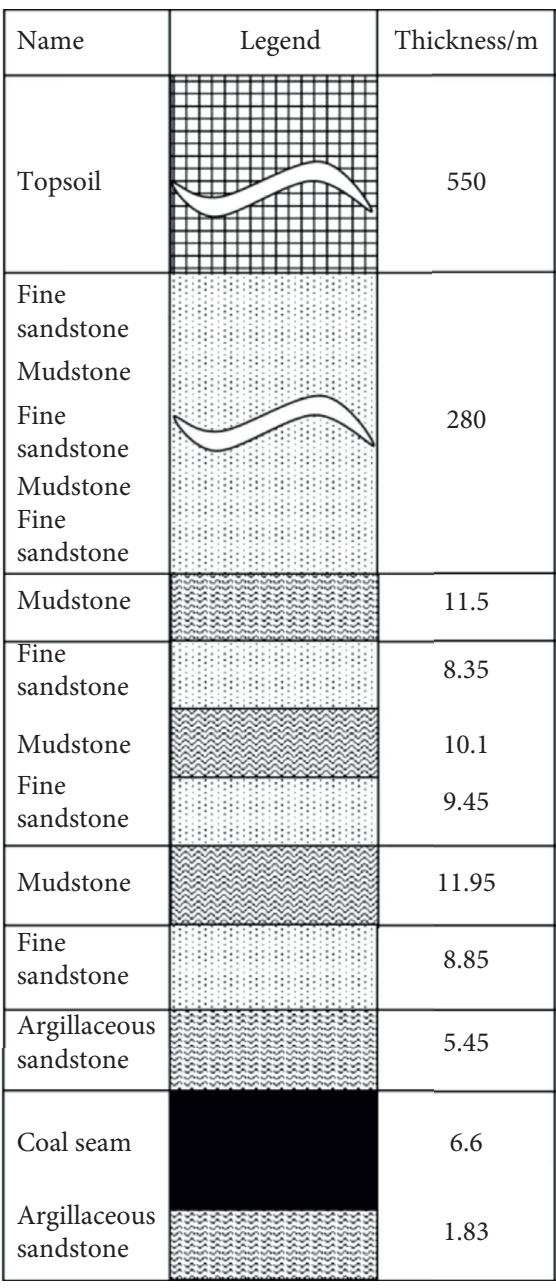

$$
A_{c}=\frac{V_{p}-V_{p}^{0}}{V_{p}^{0}},
$$

where $A_{c}$ is the velocity anomaly; $V_{p}$ is the $\mathrm{P}$-wave velocity of a certain point; $V_{p}^{0}$ is the average $\mathrm{P}$-wave velocity; If $A_{c}$ is positive, it indicates stress is concentrating in the rock. The rockburst risk increases with increasing this value. If $A_{c}$ is negative, it implies that this area is a stressreleasing area or crushed zone. Rockburst hazards are unlikely to occur in this area.

To evaluate the effect of wave velocity gradient on the risk of rockburst, the concept of wave velocity gradient coefficient $\left(G_{c}\right)$ is introduced, which is defined as

$$
G_{c}=\frac{G_{p}}{G_{p}^{c}},
$$

where $G_{p}$ is the velocity gradient at a certain point in the reverse area; $G_{p}^{c}$ is the limit velocity gradient at critical failure of the surrounding rock. The velocity gradient denotes the direction of greatest change of the velocity. In discrete data, the first-order derivatives are generally obtained for the 
surrounding eight nodes, and the maximum value is taken as the velocity gradient, as shown in Figure 4 . The velocity gradient of central grid $(m, n)$ can be expressed as

$$
G_{p}(m, n)=\max \frac{V_{p}(m, n)-V_{p}(x, y)}{d \sqrt{(m-x)^{2}++(n-y)^{2}}},
$$

where $d$ is the length of the grid; $x$ and $y$ are the vertical and horizontal numbers of each grid around it.

In order to comprehensively reflect the influence of wave velocity and wave velocity gradient on the rockburst risk, the final rockburst risk evaluation index is given as

$$
C=a A_{c}+b G_{c}=a \frac{V_{p}-V_{p}^{0}}{V_{p}^{0}}+b \frac{G_{p}}{G_{p}^{c}},
$$

where $C$ refers to rockburst risk evaluation index; $a$ and $b$ are the weights of two items. The coefficients "a" and "b" are determined according to the importance of the two terms. In this study, we consider the velocity anomaly term and the velocity gradient term as equally important. In addition, the sum of the weights should be 1 . Therefore, the values of these two coefficients are both set as $0.5 . V_{p}$ can be obtained by inversion of seismic CT technology; $G_{P}$ is calculated by equation (6); the model has a $C$ value of at most 1 , and the minimum value depends on the measured data. If $C$ is negative, it indicates that the area is in a pressure-releasing state, and the smaller the $C$ value, the greater the degree of pressure relief. In this study, the relationship between the $C$ value and rockburst risk level is shown in Table 1.

3.3. Deployment of the CT System. Figure 5 demonstrates the deployment of the CT system in LW 1301, LW 1300, and the island coal panel. LW 1301 is divided into areas A, B, and C. The blasting sources $(52,50$, and 87 for A, B, and C, respectively) were deployed in the headgate, while the receivers $(11,11$, and 18 for $\mathrm{A}, \mathrm{B}$, and $\mathrm{C}$, respectively) were deployed in the tailgate. The spaces of the blasting sources and receivers are $6 \mathrm{~m}$ and $17 \mathrm{~m}$, respectively. As for the island coal panel, two areas (D and E) were detected. The blasting sources with a space of $7 \mathrm{~m}$ were deployed in the tailgate of LW 1300, and the receivers with a space of $17 \mathrm{~m}$ were deployed in the headgate of LW 1301. The numbers of blasting sources and receivers were both 35 and 11, respectively, for the two areas.

\section{Determination of Static Stress Distribution}

4.1. Overall Distribution of Static Stress. The initial stress balance is disturbed due to coal mining. The overburden stress will transfer to the surrounding rock. Simultaneously, fracture will develop in the floor and roof strata. According to the microseismic monitoring result, as shown in Figure 6, the shape of the fracture-developed area is approximately a circle when LW 1300 was being mined. Therefore, the fracture-developed zone can be treated as a circular to study the stress distribution (see Figure 7). The radial stress $\sigma_{r}$ and tangential stress $\sigma_{\theta}$ in the longwall panel can be calculated as

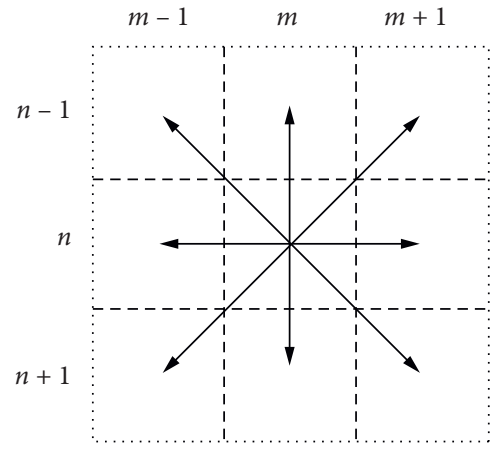

FIGURE 4: Schematic of velocity gradient for discrete data.

TABLE 1: Relationship between rockburst level and $C$ value.

\begin{tabular}{lc}
\hline Rockburst level & $C$ \\
\hline No & $C<0.5$ \\
Weak & $0.25 \leq C<0.5$ \\
Moderate & $0.5 \leq C<0.75$ \\
Strong & $0.75 \leq C \leq 1$ \\
\hline
\end{tabular}

$$
\left\{\begin{array}{l}
\sigma_{r}=\frac{\left(\sigma_{1}+\sigma_{2}\right)}{2}\left(1-\frac{r_{1}^{2}}{r^{2}}\right)-\frac{\left(\sigma_{1}-\sigma_{2}\right)}{2}\left(1-4 \frac{r_{1}^{2}}{r^{2}}+3 \frac{r_{1}^{4}}{r^{4}}\right) \cos 2 \theta, \\
\sigma_{\theta}=\frac{\left(\sigma_{1}+\sigma_{2}\right)}{2}\left(1+\frac{r_{1}^{2}}{r^{2}}\right)-\frac{\left(\sigma_{1}-\sigma_{2}\right)}{2}\left(1+3 \frac{r_{1}^{4}}{r^{4}}\right) \cos 2 \theta,
\end{array}\right.
$$

where $\sigma_{1}$ and $\sigma_{2}$ are the vertical stress and horizontal stress, respectively; $r_{1}$ is the radius of the circular tunnel; $r$ is the distance from any point in the half-plane to the origin of the coordinate.

Assuming that the depth of overlaying strata is $H, \sigma_{1}$ and $\sigma_{2}$ can be calculated as

$$
\left\{\begin{array}{l}
\sigma_{1}=\gamma H \\
\sigma_{2}=\lambda \sigma_{1}
\end{array}\right.
$$

where $\gamma$ is the bulk density of the overlying strata; $\lambda$ is a coefficient. In deep coalmines, the value of $\lambda$ is 1 [34]. Since the headgate is located on the $x$ axis, $\theta=\pi$. Hence, $\sigma_{\theta}$ can be calculated as

$$
\sigma_{\theta}=\sigma_{1}\left(1+\frac{r_{1}^{2}}{r^{2}}\right)
$$

where

$$
r_{1}=\frac{l}{2}
$$

where $l$ is the width of LW 1300. Substitute (9) and (11) into $(10), \sigma_{\theta}$ is reorganized as

$$
\sigma_{\theta}=\gamma H\left(1+\frac{l^{2}}{4 r^{2}}\right)
$$




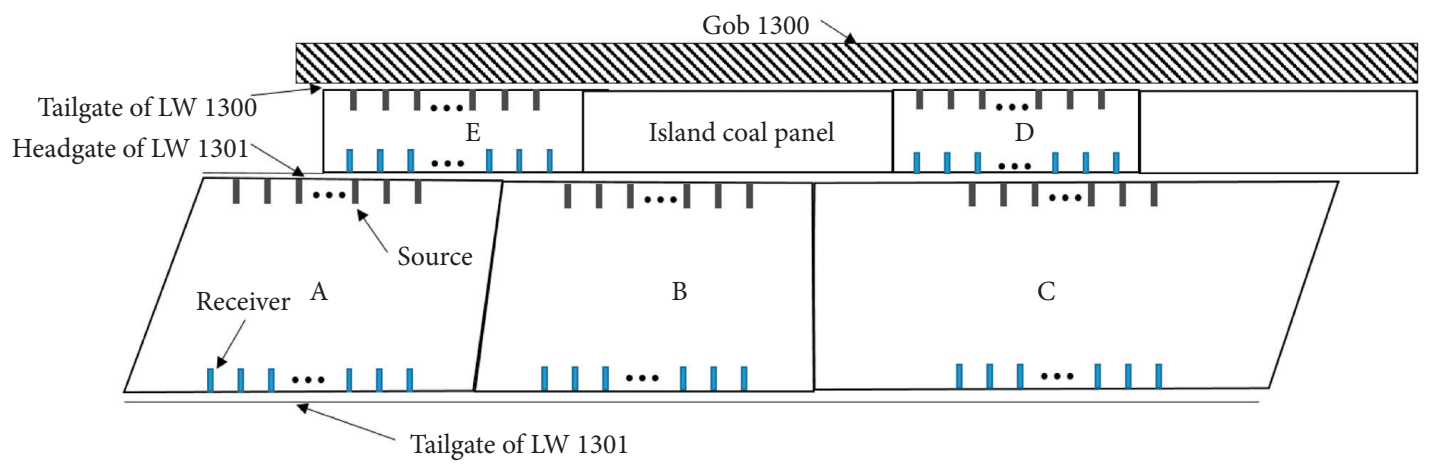

FIgUre 5: Deployment of the CT system in LW 1301 and the island coal pillar.

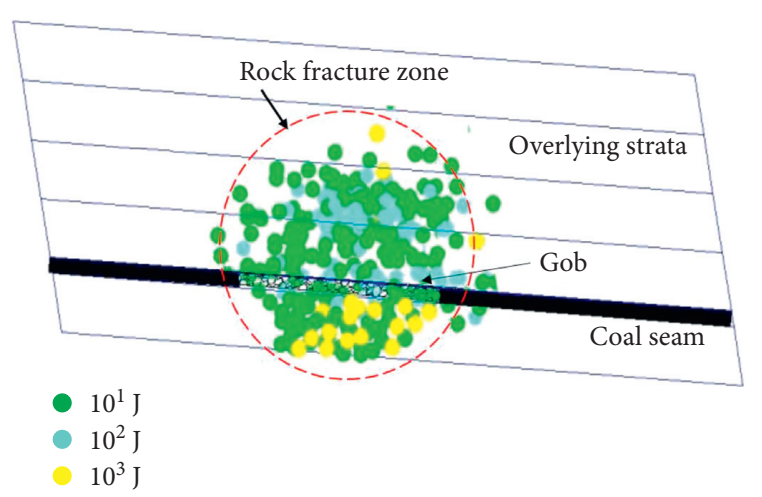

FIGURE 6: Fracture development in roof and floor of the coal seam after LW 1300 was mined.

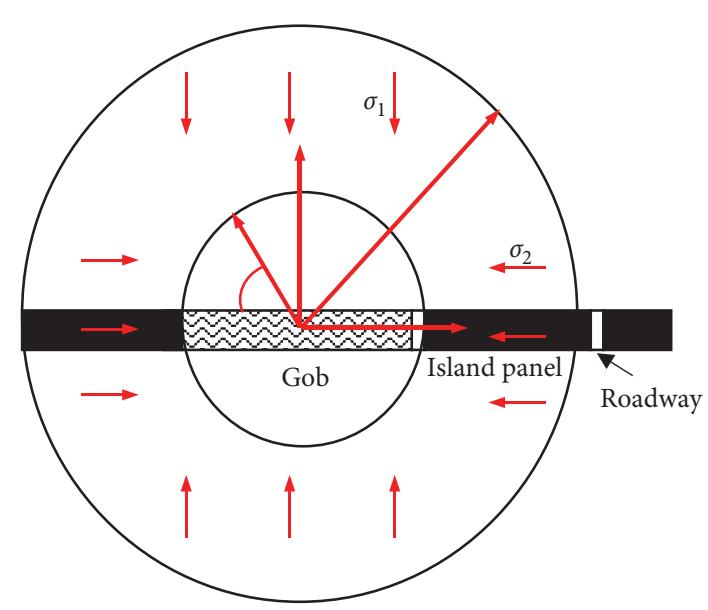

FIgURE 7: Stress distribution after LW 1300 was mined.

From, equation (12), it can be seen that $\sigma_{\theta}$ decreases with increasing $r$. Therefore, the stress in the roadway depends mainly on the distance from the goaf edge without mining influence.

In this case, the width of the island coal panel is $80 \mathrm{~m}$; the width of goaf (mined area of LW 1300) is $100 \mathrm{~m} ; r_{1}$ is $50 \mathrm{~m} ; r$ is $130 \mathrm{~m}$, and the burial depth is $1000 \mathrm{~m}$. The calculated tangential stress $\sigma_{\theta}$ is $27.4 \mathrm{MPa}$, which is much larger than the uniaxial stress of the coal mass $(18 \mathrm{MPa})$. Rockburst hazards are very likely to occur with the disturbance of coal mining.
4.2. Determination of Stress Concentration Using Seismic CT. The above mathematical model is developed assuming the overlying strata and coal seam are homogeneous. Therefore, the calculated static stress is the overall static stress without considering the stress concentration caused by geological defects. To address this problem, seismic CT was used to analyse the stress concentration degree in LW 1301 and the island panel. Figure 8 shows the distribution of the rockburst risk index in the five detected areas. This index $C$ varies from -0.5 (blue) to 0.75 (red). It can be seen that in most of the area, $C$ is less than 0.75 . The areas with higher rockburst risk $(0.5 \leq \mathrm{C}<0.75)$ are mainly located near the headgate of LW 1301 on the island coal panel side. This indicates that the headgate of LW 1301 is subject to high static stress concentration during mining LW 1300. Therefore, rock burst accidents can be easily induced on the headgate of LW 1301. The rockburst accidents that occurred on September 2015 agree well with the CT monitoring results. More pressure-releasing measures should be conducted during roadway construction and coal mining in the headgate.

Figure 9 shows the microseismic events with energy level larger than $10^{2} \mathrm{~J}$ according to the microseismic monitoring results. It can be observed that more microseismic events with larger energy $\left(10^{3} \mathrm{~J}\right)$ are distributed in the island coal panel than LW 1301. Several large-energy microseismic events are also observed near the headgate of LW 1301. The results of microseismic monitoring verified the results of seismic CT. That is, large-energy events are located in areas with high rockburst risk indexes.

\section{Evaluation of Dynamic Stress Evolution with Different Advancing Velocities}

Before mining the longwall panel, the stress of surrounding rock is in an equilibrium state. After mining starts, the potential energy and elastic strain energy stored in the overlying strata and coal seam will be dynamically transformed or released. One part of the energy will transform as elastic strain energy and store in the coal seam in front of the working face. The other part is converted into kinetic energy that will dynamically disturb the coal seam in front of the working face. The rockburst risk increases with increasing the energy 


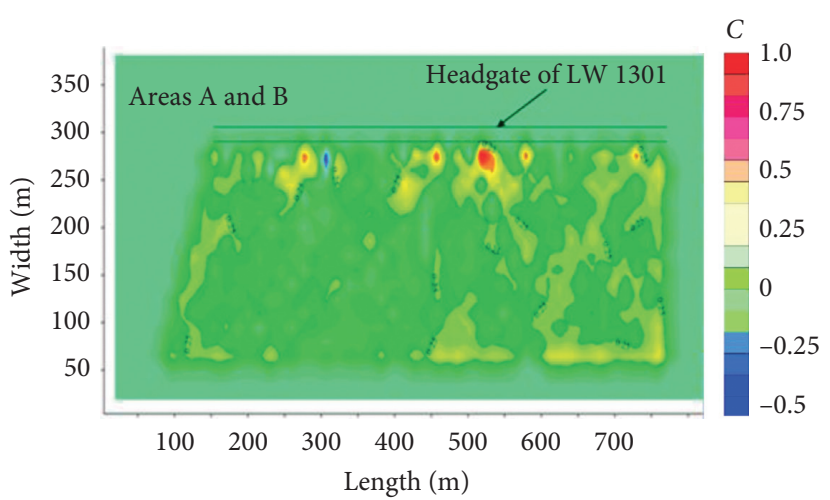

(a)

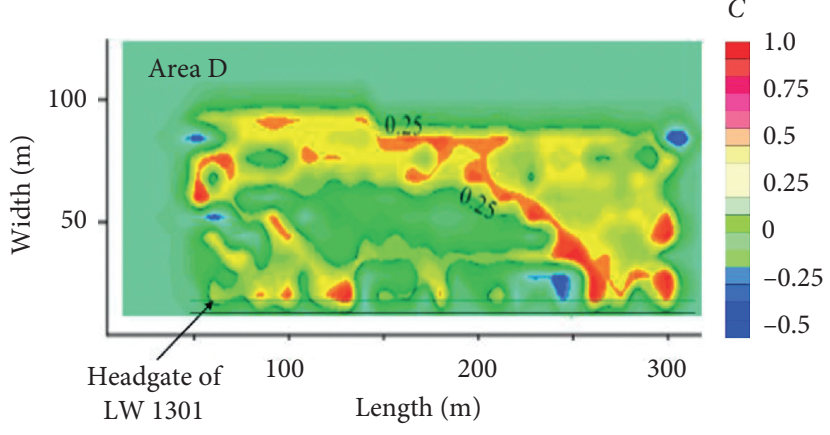

(c)

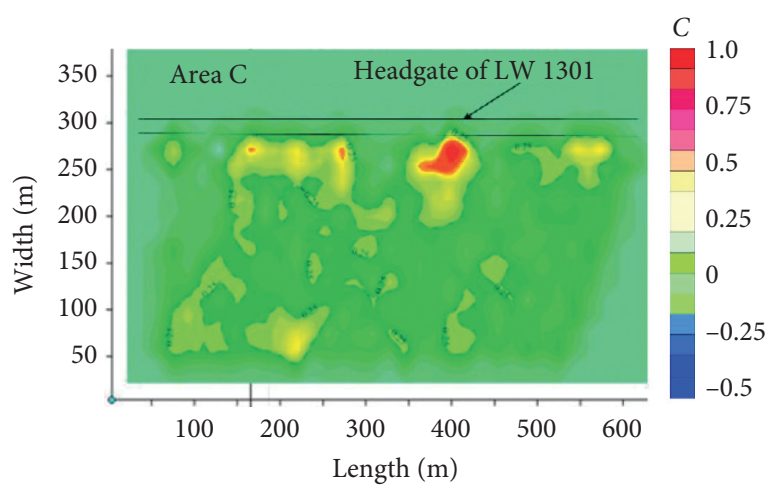

(b)

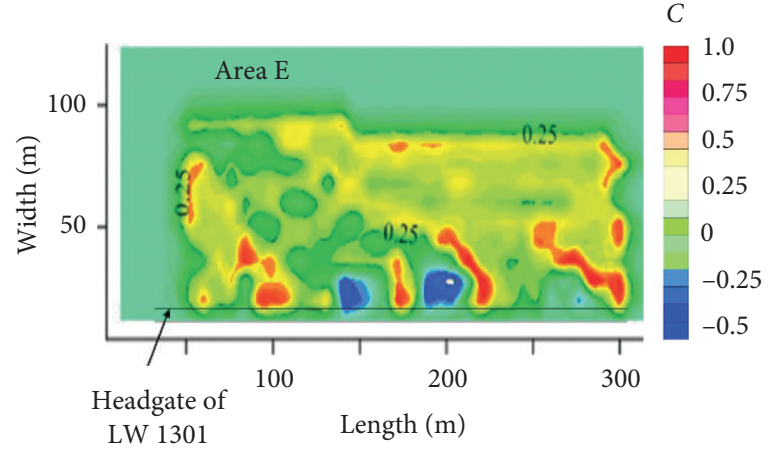

(d)

FIGURE 8: Distribution of the rockburst risk index at detection area.

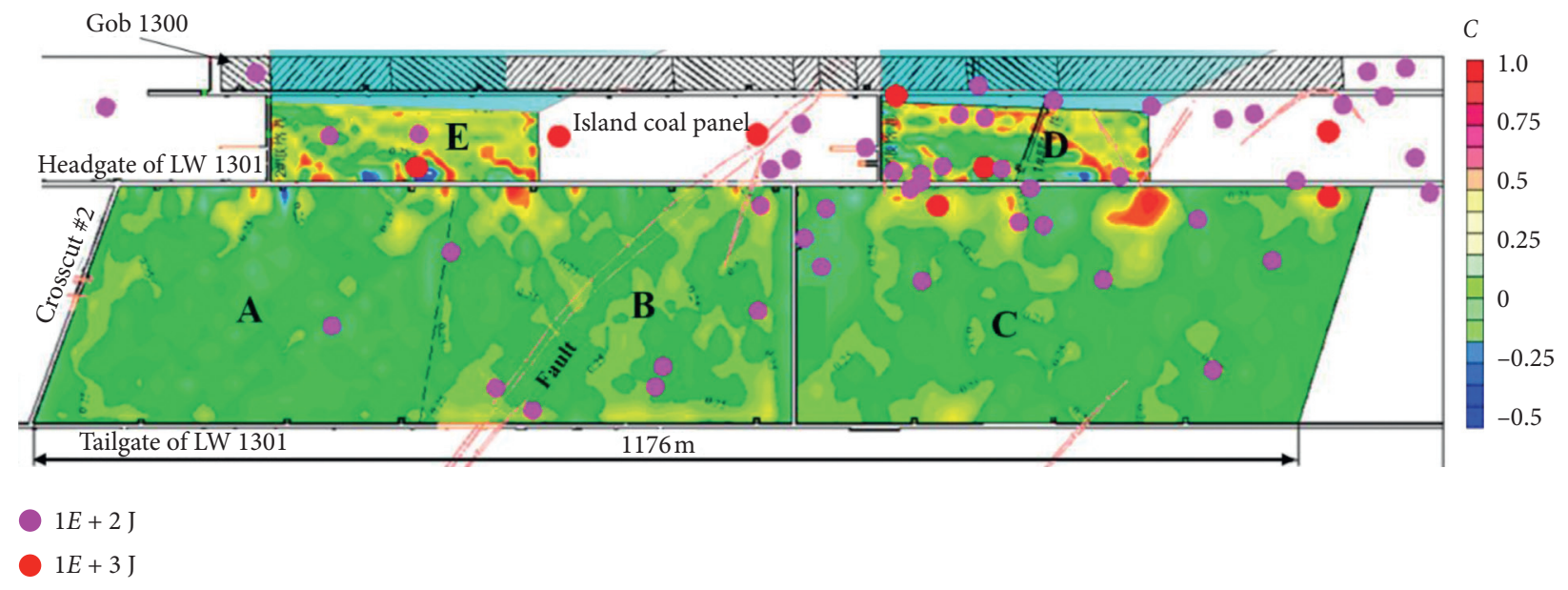

FIGURE 9: Distribution of microseismic events and rockburst risk indexes in LW 1301 and island coal panel.

conversion from potential energy of overlaying strata to kinetic energy in the coal seam.

The larger the advancing speed, the more the potential energy will be converted into elastic strain energy stored in the coal seam in a day. Therefore, it is of vital importance to determine the advancing velocity. In this study, we analyzed the influence of different advancing velocities on dynamic stress evolution in front of the working face using microseismic monitoring. The tested advancing velocities are $1.6 \mathrm{~m} / \mathrm{d}$ (low velocity), $4.0 \mathrm{~m} / \mathrm{d}$ (medium velocity), and $6.4 \mathrm{~m} / \mathrm{d}$ (high velocity). As is known, microseismic responses vary with working face advancing velocity. When working face advances at a speed of $1.6 \mathrm{~m} / \mathrm{d}$ (Figure 10(a)), only small-energy microseismic events are observed. These smallenergy microseismic events are mainly distributed close to the working face. This indicates that the mining activity has a very small influence range in the roof strata without affecting the overlying strata. When working face advances at a speed of $4.0 \mathrm{~m} / \mathrm{d}$ (Figure 10(b)), the microseismic events are mainly concentrated in the side front of the working face, including the island panel area and the headgate of LW 1301 where two clusters of events are observed: large-energy 


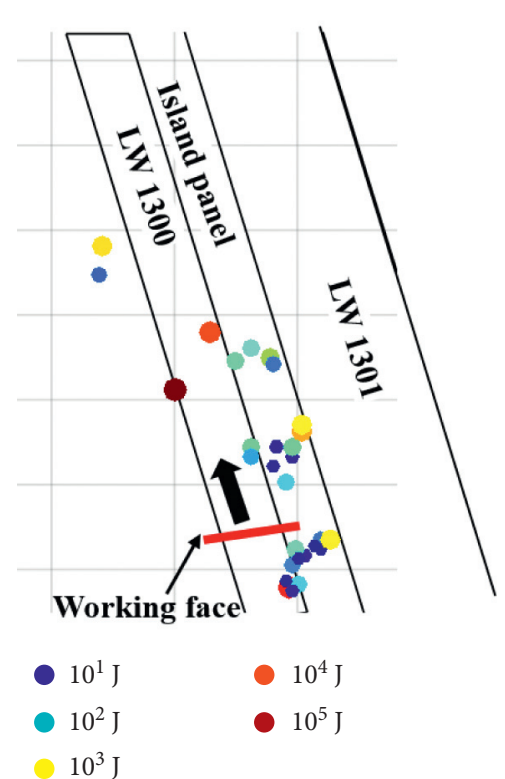

(a)

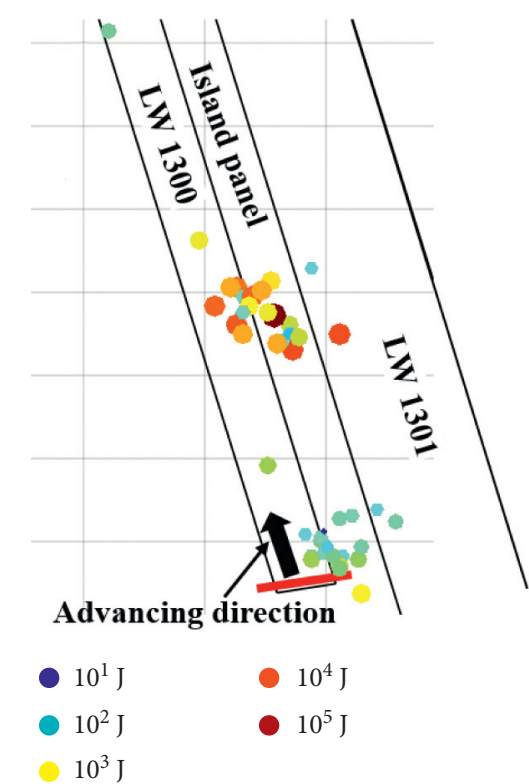

(b)

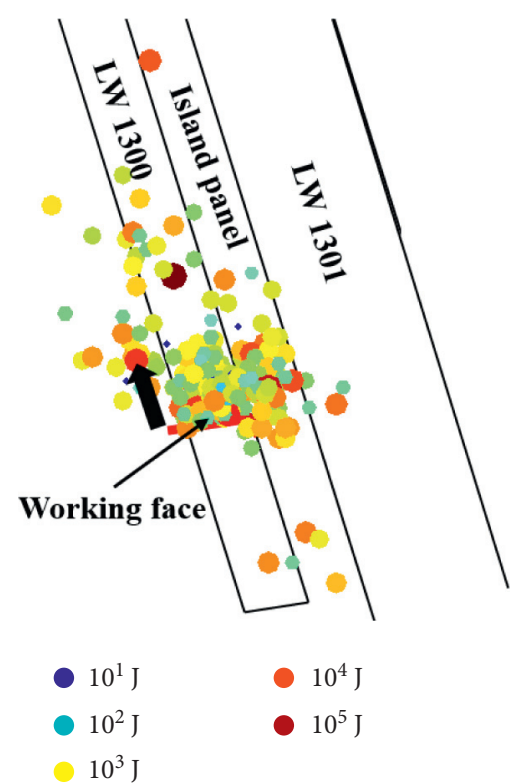

(c)

Figure 10: Distribution of microseismic events around the working face at different advancing speeds: (a) $1.6 \mathrm{~m} / \mathrm{d}$; (b) $4.0 \mathrm{~m} / \mathrm{d}$; (c) $6.4 \mathrm{~m} / \mathrm{d}$.

microseismic events are concentrated at about $600 \mathrm{~m}$ in front of the working face near the main fault, while at $100 \mathrm{~m}$, the energy of most of the microseismic events is relatively small. These small-energy microseismic events have little influence on mining. It is speculated that at medium advancing velocity, more fractures are generated in the highlevel rock strata, resulting in the fault activation. When the mining speed is increased to $6.4 \mathrm{~m} / \mathrm{d}$, the number and energy magnitude of microseismic events around the working surface increase significantly, as shown in Figure 10(c). Microseismic events with energy larger than $10^{2} \mathrm{~J}$ are densely distributed at $200 \mathrm{~m}$ in front of the working face. This is caused by the rapid evolution of dynamic stress and the rapid release of elastic potential energy in the coal seam. It can be seen that the mining velocity directly influences the evolution of the spatial morphology of the surrounding rock and the distribution range of the dynamic and static abutment pressure. According to the comparison results, $4 \mathrm{~m} / \mathrm{d}$ (medium velocity) was determined to be the reasonable mining velocity for mining of LW 1300 as at this velocity both rockburst risk and productivity are acceptable.

It should be noted that this section studies the relationship between the mining speed and the distribution of microseismic events in front of the working face. By analyzing the distribution intensity and the energy of the event, we can indirectly and qualitatively analyse the rockburst risk. However, the quantitative relationship between the mining speed and rockburst risk is not studied in this paper and will be focused on the future work.

\section{Conclusions}

The combined action of high static stress and dynamic stress in the protective panel may cause rockburst hazards in the gateway of next longwall panel pending mining. To evaluate the distribution of static and dynamic stress in the protective panel, this study proposes integrated microseismic and CT monitoring methods and achieves the following conclusions:

(1) The proposed mathematical model is convenient for calculating the overall static stress distribution in the protective panel.

(2) The rockburst risk evaluation index calculated by velocity anomaly and velocity gradient using seismic CT can accurately evaluate stress concentration in the protective coal panel.

(3) The extent of dynamic stress evolution caused by different working face advancing velocities is determined by microseismic monitoring. A medium advancing velocity $(4.0 \mathrm{~m} / \mathrm{s})$ is recommend during mining the longwall panel, which can ensure mining safety and improve mining productivity simultaneously.

This integrated microseismic and CT monitoring method has been successfully applied in Longyun coalmine. However, the proposed method may be insufficient to evaluate dynamic disasters in other complex geotechnical projects. New rockburst evaluation indices should be introduced according to specific geological condition and engineering requirements.

In addition, in the developed mathematical model, the overlying strata are simplified as a complete strata, while actually the overlying strata are fractured and hanging with complex stress redistribution. Therefore, in the future work, the mathematical model should be calibrated by the spatial structure of the overlying strata which can be determined by measuring ground surface subsidence. It is worthwhile mentioning that in other ultradeep mines with 
high rockburst risks, other real-time monitoring methods such as real-time stress online monitoring are strongly recommended.

\section{Data Availability}

Data are available on request.

\section{Conflicts of Interest}

The authors declare that they have no conflicts of interest.

\section{Acknowledgments}

This work was supported in part by the State Key Research Development Program of China under grant no. 2016YFC0801408, in part by the National Natural Science Foundation of China under grant no. 51674014, in part by the Key Project of National Natural Science Foundation under grant no. 51634001, in part by Shandong Energy Group Company Limited under grant no. 2019SDZY02 and in part by State Key Laboratory of Mining Disaster Prevention and Control Co-founded by Shandong Province and The Ministry of Science and Technology under grant number (MDPC202007).

\section{References}

[1] P. Yan, Z. Zhao, W. Lu, Y. Fan, X. Chen, and Z. Shan, "Mitigation of rock burst events by blasting techniques during deep-tunnel excavation," Engineering Geology, vol. 188, pp. 126-136, 2015.

[2] C. S. Ma, W. Z. Chen, X. J. Tan, H. M. Tian, J. P. Yang, and J. X. Yu, "Novel rockburst criterion based on the TBM tunnel construction of the Neelum-Jhelum (NJ) hydroelectric project in Pakistan," Tunnelling and Underground Space Technology, vol. 81, pp. 391-402, 2018.

[3] J. Hedley, V. Menon, L. Cho, and A. J. McShane, "Fifth generation troponin T assay is subject to antibody interference," Clinica Chimica Acta; International Journal of Clinical Chemistry, vol. 505, pp. 98-99, 2020.

[4] J. Zhang, F. Jiang, J. Yang, W. Bai, and L. Zhang, "Rockburst mechanism in soft coal seam within deep coal mines," International Journal of Mining Science and Technology, vol. 27, no. 3, pp. 551-556, 2017.

[5] J. Zhou, X. Li, and H. S. Mitri, "Evaluation method of rockburst: state-of-the-art literature review," Tunnelling and Underground Space Technology, vol. 81, pp. 632-659, 2018.

[6] J. Zhang, Y. Wang, Y. Sun, and G. Li, "Strength of ensemble learning in multiclass classification of rockburst intensity," International Journal for Numerical and Analytical Methods in Geomechanics, vol. 44, no. 13, pp. 1833-1853, 2020.

[7] T. H. Ma, C. A. Tang, L. X. Tang, W. D. Zhang, and L. Wang, "Rockburst characteristics and microseismic monitoring of deep-buried tunnels for Jinping II hydropower station," Tunnelling and Underground Space Technology, vol. 49, pp. 345-368, 2015.

[8] J. Zhang, F. Jiang, S. Zhu, and L. Zhang, "Width design for gobs and isolated coal pillars based on overall burst-instability prevention in coal mines," Journal of Rock Mechanics and Geotechnical Engineering, vol. 8, no. 4, pp. 551-558, 2016.

[9] B.-X. Huang, C.-y. Liu, B.-S. Zhen, and Q.-y. Cheng, "Distribution abutment pressures on laneway pillars for superwide isolated fully mechanized top coal caving face," Yantu Gongcheng Xuebao (Chinese Journal of Geotechnical Engineering), vol. 29, no. 6, pp. 932-937, 2007.

[10] S. Zhu, Y. Feng, F. Jiang, and J. Liu, "Mechanism and risk assessment of overall-instability-induced rockbursts in deep island longwall panels," International Journal of Rock Mechanics and Mining Sciences, vol. 106, pp. 342-349, 2018.

[11] Y. Sun, J. Zhang, G. Li et al., "Determination of Young's modulus of jet grouted coalcretes using an intelligent model," Engineering Geology, vol. 252, pp. 43-53, 2019.

[12] Y. Sun, J. Zhang, G. Li, Y. Wang, J. Sun, and C. Jiang, "Optimized neural network using beetle antennae search for predicting the unconfined compressive strength of jet grouting coalcretes," International Journal for Numerical and Analytical Methods in Geomechanics, vol. 43, no. 4, pp. 801813, 2019.

[13] J. Zhang, D. Li, and Y. Wang, "Predicting uniaxial compressive strength of oil palm shell concrete using a hybrid artificial intelligence model," Journal of Building Engineering, vol. 30, Article ID 101282, 2020.

[14] J. Zhang, D. Li, and Y. Wang, "Toward intelligent construction: prediction of mechanical properties of manufactured-sand concrete using tree-based models," Journal of Cleaner Production, vol. 258, Article ID 120665, 2020.

[15] J. Zhang, D. Li, and Y. Wang, "Predicting tunnel squeezing using a hybrid classifier ensemble with incomplete data," Bulletin of Engineering Geology and the Environment, vol. 79, no. 6, pp. 3245-3256, 2020.

[16] L. Dou, T. Chen, S. Gong, H. He, and S. Zhang, "Rockburst hazard determination by using computed tomography technology in deep workface," Safety Science, vol. 50, no. 4, pp. 736-740, 2012.

[17] W. Cai, L. Dou, A. Cao, S. Gong, and Z. Li, "Application of seismic velocity tomography in underground coal mines: a case study of Yima mining area, Henan, China," Journal of Applied Geophysics, vol. 109, pp. 140-149, 2014.

[18] A. Cao, L. Dou, W. Cai, S. Gong, S. Liu, and Y. Zhao, "Tomographic imaging of high seismic activities in underground island longwall face," Arabian Journal of Geosciences, vol. 9, no. 3, p. 232, 2016.

[19] K. Luxbacher, E. Westman, P. Swanson, and M. Karfakis, "Three-dimensional time-lapse velocity tomography of an underground longwall panel," International Journal of Rock Mechanics and Mining Sciences, vol. 45, no. 4, pp. 478-485, 2008.

[20] D. Eberhart-Phillips, D.-H. Han, and M. Zoback, "Empirical relationships among seismic velocity, effective pressure, porosity, and clay content in sandstone," Geophysics, vol. 54, no. 1, pp. 82-89, 1989.

[21] W. C. Zhu, Z. H. Li, L. Zhu, and C. A. Tang, "Numerical simulation on rockburst of underground opening triggered by dynamic disturbance," Tunnelling and Underground Space Technology, vol. 25, no. 5, pp. 587-599, 2010.

[22] J. Wang and J. Zhang, "Preliminary engineering application of microseismic monitoring technique to rockburst prediction in tunneling of Jinping II project," Journal of Rock Mechanics and Geotechnical Engineering, vol. 2, no. 3, pp. 193-208, 2010.

[23] D. Li, J. Zhang, C. Wang, Y. Chen, and D. Ge, "Assessing rockburst hazards using a self-developed real-time microseismic monitoring system in a deep-sea goldmine," IEEE Access, vol. 7, pp. 134360-134371, 2019.

[24] D. Li, J.-f. Zhang, C.-w. Wang, and F.-x. Jiang, "Propagation patterns of microseismic waves in rock strata during mining: 
an experimental study," International Journal of Minerals, Metallurgy, and Materials, vol. 26, no. 5, pp. 531-537, 2019.

[25] N. Cook, "The application of seismic techniques to problems in rock mechanics," International Journal of Rock Mechanics and Mining Sciences \& Geomechanics Abstracts, vol. 1, no. 2, pp. 169-179, 1964.

[26] C. Srinivasan, S. K. Arora, and S. Benady, "Precursory monitoring of impending rockbursts in Kolar gold mines from microseismic emissions at deeper levels," International Journal of Rock Mechanics and Mining Sciences, vol. 36, no. 7, pp. 941-948, 1999.

[27] A. Leśniak and Z. Isakow, "Space-time clustering of seismic events and hazard assessment in the Zabrze-Bielszowice coal mine, Poland," International Journal of Rock Mechanics and Mining Sciences, vol. 46, no. 5, pp. 918-928, 2009.

[28] C.-P. Lu, G.-J. Liu, Y. Liu, N. Zhang, J.-H. Xue, and L. Zhang, "Microseismic multi-parameter characteristics of rockburst hazard induced by hard roof fall and high stress concentration," International Journal of Rock Mechanics and Mining Sciences, vol. 76, pp. 18-32, 2015.

[29] Q. Zhu, Y. Feng, M. Cai, J. Liu, and H. Wang, "Interpretation of the extent of hydraulic fracturing for rockburst prevention using microseismic monitoring data," Journal of Natural Gas Science and Engineering, vol. 38, pp. 107-119, 2017.

[30] P. Gilbert, "Iterative methods for the three-dimensional reconstruction of an object from projections," Journal of Theoretical Biology, vol. 36, no. 1, pp. 105-117, 1972.

[31] D. R. Tweeton, A Tomographic Computer Program with Constraints to Improve Reconstructions for Monitoring in Situ Mining Leachate, U.S. Department of the Interior, Bureau of Mines, Pittsburgh, PA, USA, 1988.

[32] V. Schmid, "Cell transformation in isolated striated muscle of hydromedusae independent of DNA synthesis," Experimental Cell Research, vol. 94, no. 2, pp. 401-408, 1975.

[33] S. J. Gibowicz and A. Kijko, An Introduction to Mining Seismology, Elsevier, Amsterdam, Netherlands, 2013.

[34] P. Sheorey, "A theory for in situ stresses in isotropic and transverseley isotropic rock," International Journal of Rock Mechanics and Mining Sciences \& Geomechanics Abstracts, vol. 31, no. 1, pp. 23-34, 1994. 